\title{
RitUALES DE INVOCACIÓN A DEIDADES ANCESTRALES ZOQUES
}

\author{
Laureano Reyes Gómez
}

Resumen: En este trabajo se estudia la persistencia de prácticas de rituales ancestrales zoques, en la invocación a deidades en eventos donde se requiere el concurso de sus dioses nativos. No obstante el largo proceso de evangelización, este conocimiento está en manos de los católicos tradicionalistas identificados localmente como "costumbreros", y lo desarrollan en tres planos de espacios socioreligiosos muy importantes: el ambiente privado (casas, cuevas, cerros), el público, en contextos religiosos católicos (la iglesia, la ermitayotros lugares "sagrados"), yel nivel público social, aquel que se desarrolla en eventos oficiales de difusión cultural, como muestra del folclore nativo zoque, y que se presenta a menudoteatralizado.

Palabras clave: Rituales, invocación, deidades, zoques.

Enviado a dictamen: 17 de septiembre de 2011 Aprobación: 11 de octubre de 2011

Revisiones: 1

Dr. Laureano Reyes Gómez, doctor en Ciencias Sociales por El Colegio de la Frontera Norte, labora en el Instituto de Estudios Indígenas de la Universidad Autónoma de Chiapas, en San Cristóbal de Las Casas, Chiapas. Temas de especialización: Etnogerontología social, Antropología médica. Correo electrónico: reylau2001@hotmail.com.
Abstract: In this paper we study the persistence, despite the long process of evangelization, Zoques ancestral ritual practices in the invocation of native deities, in events where they need the assistance of their gods. This knowledge is held by traditional Catholics self identified locally as "costumbreros" and develop in three planes of space very important socioreligious: the private environment (houses, caves, hills), the Catholic public contexts (church, the chapel and other "sacred" places), and the social public, one that takes place at official events of cultural diffusion, as shown in native Zoque folklore (theatrical).

Keywords: Rituals, invocation, deities, Zoques.

\section{Introducción}

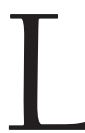
a región de los zoques está ubicada en el extremo noroccidental del estado de Chiapas y zonas aledañas de los estados de Oaxaca y Tabasco (Villa, 1975: 17). Su población está fraccionada por motivos religiosos en tres segmentos perfectamente diferenciados e identificados: los "costumbreros", los católicos y los adventistas (Córdoba, 1975: 194).

Este trabajo tiene el propósito de exponer cómo, a pesar del largo proceso de evangelización que han sufrido los pueblos indígenas, los zoques aún conservan 
vestigios de prácticas religiosas antiguas que se pueden observar en ritos ceremoniales específicos, ya sean propios de sus costumbres ancestrales (ritos de fertilidad, para aplacar la ira de las deidades), ya como complemento de rituales cristianos (celebración de los santos patrones), o bien como muestra pública del folclore nativo (asistencia a eventos culturales oficiales). Estas prácticas están depositadas en un sector minoritario de la población, que se identifica como "costumbrero" o "católico tradicionalista".

Aunque no se cuenta con datos estadísticos sobre el número de practicantes considerados "costumbreros", se estima que, sólo en la cabecera municipal de Ocotepec, el segundo municipio con mayor número de hablantes monolingües de zoque, alrededor de unas veinte familias practican los ritos de "la costumbre" (Rodríguez León, "Sobre la costumbre zoque").

La ritualidad "costumbrera" está a cargo principalmente de ancianos tradicionalistas, que desempeñan cargos religiosos instituidos por la Iglesia Católica desde la época colonial. Es decir, se trata de personas que generalmente combinan el cristianismo con elementos de la religiosidad nativa zoque: invocan a sus deidades ancestrales algunas veces bajo la figura de santos católicos, oran en lengua zoque, acompañan sus ritos con música de flauta y tambor, ejecutan danzas rituales, en situaciones especiales realizan sacrificios de aves, y la ingesta de alcohol en sus ceremonias es un uso común. El ritual no necesariamente se realiza en el templo católico, sino en los lugares de trabajo, las cuevas, los cerros y otros sitios considerados sagrados como las ermitas. Los "costumbreros", entonces, mantienen las expresiones religiosas antiguas de la etnia, aunque con una fuerte carga sincrética, y en ellos recae, en buena medida, la identidad cultural del grupo.

Sin embargo, los "costumbreros", a los ojos de los demás grupos religiosos, tienen una connotación generalmente negativa: para los católicos son "atrasados, no entienden como las gentes y además son muy borrachos"; mientras que para los adventistas, además de "atrasados", "viven en el error y son idólatras" (Córdoba, Op. Cit: 195).

La práctica de esta religiosidad obedece, en buena medida, a que está sustentada en la cosmovisión y cultura general del grupo indígena. Así, sus deidades están presentes bajo diferentes manifestaciones en la vida diaria. De igual forma sucede con su percepción del Inframundo y sus necesidades espirituales en el Supramundo. Los ancianos "costumbreros" algunas veces manejan las artes de la medicina y la magia, y son vistos como los depositarios de las costumbres del grupo, especialmente en los ritos ceremoniales de fertilidad.

\section{Las deidades zoques}

La religión antigua de los zoques es de tipo animista. Creen en una constelación de dioses, todos ellos vivos, a menudo jóvenes, excelsos, que nunca mueren y son extremadamente poderosos. Dependiendo del comportamiento humano observado en la vida terrena, las deidades pueden brindar premios o castigos. Generalmente aparecen en parejas bajo la figura de hombre o mujer, o bien, macho o hembra. Cuando la deidad es femenina, es percibida en extremo hermosa físicamente, y de mayor poder que el hombre. De hecho, en lengua nativa existen dos palabras para hacer referencia a lo hermoso, lo bello, lo agradable, e incluso lo sabroso: suñi y sa'sabö. La primera expresión es de uso común; la segunda, de uso reverencial, y está reservada a las deidades. Sólo a los dioses puede otorgárseles la categoría de excelsos; los humanos han de conformarse con ser simplemente bellos. ${ }^{1}$

La residencia de los dioses está en el Inframundo, aunque hacen presencia en la vida terrena a su voluntad o por invocación humana. Según la percepción zoque existen tres inframundos y un mundo terrenal; todos estos espacios coexisten en forma simultánea, es decir, son mundos paralelos a la vida terrena, con la diferencia de que en los diversos inframundos el tiempo no existe, 
toda vez que está congelado, atrapado en la eternidad; esta es una de las razones del porqué sus dioses nunca envejecen, ${ }^{3}$ a diferencia de los santos católicos, muchos de los cuales son representados como ancianos, que, además de cansarse, corren el riesgo de morir y, en consecuencia, perder poder, como se asegura sucede con San Marcos Evangelista, quien, dada su avanzada edad, "ya se cansa".

El primer inframundo se llama Tsu'an (literalmente: "el umbral a la noche"), y es el mundo del Encanto. Ahí van a vivir las personas que murieron en guerra o por fenómenos naturales. Es un mundo de fiesta, todo es felicidad eterna. No existe la enfermedad, la tristeza, la vejez, las preocupaciones y otros pesares terrenales. Este territorio está gobernado por Kotsök pöt o Kotsök yomo ( Kotsök quiere decir “cerro", pöt, “señor”; y yomo, "mujer casada"); es decir, los "Dueños o Señores del Cerro"). En la percepción cristiana este elemento fue usado para sustituirlo por la figura del santo patrón, como veremos más adelante (vid. infra, p. 9).

El segundo inframundo es conocido como I'ps töjk ( "laberinto"). Es el lugar donde van a vivir las personas que murieron por causas naturales, incluidos los bebés que perdieron la vida a edades tempranas y madres muertas durante el parto. En este inframundo existe un tribunal compuesto por trece ancianos que se encarga de juzgar al nuevo residente, según el comportamiento que observó en la vida terrena; el público asistente al juicio son sus antiguos vecinos, ahora residentes en I’ps töjk; en consecuencia, conocen al nuevo huésped, y pueden apoyar o hundir al indiciado. El Gran Tribunal está compuesto por trece integrantes ancianos, de los cuales seis lo defenderán y seis más lo acusarán, mientras que el decimotercer elemento tiene la delicada tarea de emitir el veredicto final. Si tuvo una vida ejemplar en tierra, como premio ocupará un puesto en la estructura de poder, y podría alcanzar la categoría de gran funcionario en este inframundo; en cambio, si tuvo mal comportamiento en vida terrena, como castigo irá a la cárcel, cuyas paredes son de oro. El tiempo en I'ps töjk está atrapado. Los residentes premiados por su buen comportamiento en la vida terrena gozan de felicidad eterna. Los instrumentos de labranza y de cocina cobran vida por sí mismos, y son ellos los que hacen las faenas.

El tercer inframundo se conoce como Pagujk tsu ("la media noche"). Este territorio está reservado para los suicidas. Es un mundo de sombras. Sus residentes buscan insistentemente la salida, pero no la encuentran, toda vez que están aquí por elección propia. Sufren angustia y soledad. El tiempo está congelado. La deidad que gobierna este inframundo es Ka'uböt ( $k a^{\prime} u$ significa "muerte", y böt puede traducirse como "persona", "ente"): la personificación de la muerte. Ka'uböt retiene a sus residentes en su territorio, los envuelve en un mar de sombras.

Con el proceso de evangelización, la religión nativa zoque sufrió cambios sustanciales, y, en el mejor de los casos, se fusionó con los elementos cristianos. La mayoría de las veces, quienes siguieron la práctica clandestina de los rituales nativos, al momento de ser sorprendidos, fueron acusados de idolatría.

Sin embargo, para evangelizar a los nativos, los españoles usaron algunas figuras similares a los antiguos dioses prehispánicos , y les pusieron nombres castellanos. Evidentemente, hubo dificultades para hacer las referencias, toda vez que cada concepción parte de culturas distintas. Por ejemplo, en la concepción zoque, las deidades siempre se identifican en pareja, unas veces son malas, otras, buenas. Cuando la deidad zoque era identificada en su papel de malo, no dudaron en catalogarla como el demonio, y así, el diablo, a decir de Báez-Jorge, utilizó varios "disfraces" (2003). Surgieron, entonces, distintas formas de identificarlo.. Pocas figuras encajaron tan bien en la estructura religiosa cristiana, como veremos a continuación.

"El Malo" fue el epíteto que usaron los misioneros hispánicos para referirse al Diablo (Báez-Jorge, 2003: 446). En lengua nativa se utilizan varias formas, aunque existe un término genérico que lo define como tal: Ya`tsi bö (Yátsi equivale a "malo"; bö es el agentivo: el Malo). 
Sin embargo, existen muchas otras formas de hacer referencia al "malo", unas de las más importantes las que citamos a continuación:

Jokoisto (Joko equivale a "humo", isto, "espejo"), es decir, Espejo Humeante, dios de la guerra. Este dios tiene como característica principal que no concede piedad aún rendido el enemigo, y lo destruye sin compasión. Se invoca para que infunda valor, coraje, inmisericordia, fuerza y sed de venganza. Los evangelizadores encontraron razones suficientes para considerar a Jokoisto bajo la figura del mal.

Mönku' (Mö es igual a "rayo", $n$ es un marcador posesivo de segunda persona en singular, y ku' significa "árbol"). Es decir, Rayo del Árbol, nombre con el que se conoce al hombre-rayo. El Rayo del Árbol se concibe como un anciano muy fuerte, que vive en la copa de los árboles y anda desnudo. Para convertirse en rayo brinca hacia el cielo gritando y se posa en las nubes. ${ }^{4}$ Existen en la concepción zoque cuatro tipos de hombres-rayo, los que se distinguen por color, origen y acciones, a saber: el Rayo Azul es benévolo, viene del Norte y propicia abundantes lluvias; el Rayo Blanco viene del Sur, y actúa cuando hay calor provocando sequías; se considera propio de los rayos "secos", que pueden caer en pleno día soleado sin presagio de lluvia; el Rayo Verde "se asoma" por el Oriente, y se hace acompañar de nortes, tormenta eléctrica y vientos huracanados; por último, el Rayo Negro, que es el del poniente, terriblemente destructivo, y el responsable de incendios, aunque muestra cierta preferencia por impactar en templos católicos. ${ }^{5}$ Razones sobran, en la percepción cristiana, para considerarlo el Diablo mismo. No obstante, según los zoques, el "Diablo" podría ser invocado en su papel de hombre-rayo para propiciar o detener lluvias. La esposa del rayo, toda vez que está asociada al agua, es la rana. Esta doble concepción hace del "costumbrero", desde la representación cristiana, un ser ambivalente; sin embargo, para este último, su rito de invocación no es al mal, sino al dios de la lluvia, a la fertilidad.
Un ente femenino terriblemente maléfico es Nöwayomo (Nöes "agua"; way es un locativo: "oriunda de"; y yomo "mujer casada"). Podría traducirse como "Mujer oriunda del agua", aunque localmente a este personaje se le conoce en castellano con el nombre de "Sirenita". Se cree que en realidad Nöwayomo es una víbora, y gusta seducir a los hombres haciéndose pasar por la novia, esposa o amante. Ella se pasea desnuda libremente en las márgenes de los ríos, y es seductora. El hombre cae en la tentación, pero Nöwayomo le guarda una sorpresa, pues tiene la vagina dentada. Evidentemente, este personaje es identificado como una variación de Satanás o el diablo-serpiente.

Otro personaje de la cosmovisión zoque que encajó a la perfección en la iconografía cristiana fue la concepción de la tona o tonalli, animal compañero o alter ego, interpretado bajo la figura del "ángel de la guarda”. En la concepción indígena, tanto el alter ego como la persona son interdependientes: uno cuida del otro y ambos corren suertes paralelas. En la visión zoque, un individuo podría tener hasta 13 "ángeles de la guarda" o animales compañeros. Dependiendo de la combinación de tipos de animales, éstos podrían ser fuertes o débiles, arrojados o cobardes, tímidos o extrovertidos, de costumbres diurnas o nocturnas, y todos estos elementos definen la personalidad o carácter del individuo. La concepción de la tona no fue del todo satanizada.

Una deidad femenina muy importante es Sawaoko (Sawa es "viento", Oko significa "abuela", en su forma reverencial): "La abuela-viento". Es una mujer en extremo bella; sus cabellos son largos, miden como tres metros de longitud. Para provocar vientos baila haciendo girar su larga cabellera, y el ruido que produce es "wis, wis". Los vientos pueden ser dañinos o benéficos, según cada circunstancia.

Existen otras muchas deidades, sin embargo, no podemos dejar de referir a los dueños del cerro, de ríos, de pueblos desaparecidos, de panteones, de cuevas y muchos otros sitios considerados como de "encanto" o 
“sagrados". Son los mencionados Kotsökpöt o Kotsökyomo. Ellos son amos y señores de todo cuanto existe en el suelo y subsuelo, y sus riquezas son infinitas. ${ }^{6}$ Especialmente se considera como "tesoro" el agua, el gas natural, el petróleo, piedras preciosas y el barro destinado a la alfarería. Son considerados dioses de la fertilidad o Madre/Padre Tierra. A ellos se recurre en petición de abundantes cosechas y riquezas varias. Todo parece indicar que la figura del "Señor del Cerro" fue utilizada por los evangelizadores para sustituirla por la imagen del santo patrón del pueblo, pues ambos cumplen básicamente las mismas funciones. Así, por ejemplo, en Chapultenango algunas veces la Virgen del Rosario es equiparada a la Señora del volcán Chichón. Como las versiones de que el Señor del Cerro lo equiparan al diablo, pues se presume que da riquezas a cambio del alma del sujeto beneficiado.

\section{Invocación a deidades ancestrales}

La invocación a deidades ancestrales son ceremonias que se desarrollan bajo tres planos socio-religiosos bien definidos: la dimensión privada, la pública, en contextos religiosos, y la pública social, por medio de eventos de difusión cultural, como muestra del folclore zoque. Los eventos privados se desarrollan generalmente en las casas, las montañas, las cuevas y otros sitios considerados "sagrados" o que tienen "encanto". La celebración pública religiosa se lleva a cabo principalmente en la iglesia, las ermitas y los panteones. Y la pública social, como ya se mencionó, a través de eventos culturales, generalmente de carácter oficial.

Respecto a los eventos privados, dada su naturaleza, contamos con pocos registros de idolatría que datan de la época de la Colonia, y que dan cuenta del proceso de evangelización al que los indígenas de la región se vieron sometidos. ${ }^{7}$ Sin embargo, recientemente rescatamos un rezo de un campesino al Señor del Cerro, al iniciar sus labores agrícolas.
Como ejemplo de ceremonias públicas de invocación en contextos religiosos, tenemos el caso de la erupción en marzo y abril de 1982 del volcán Chichón, situación ante la que los "costumbreros" invocaron a la Señora del Volcán para aplacar su ira.

Finalmente, los eventos públicos sociales se desarrollan en espacios de exhibición del folclore nativo auspiciados, generalmente, por organismos oficiales. Veamos el desarrollo ceremonial en cada espacio socioreligioso.

\section{a. Invocación de fertilidad al Señor o Señora del Cerro}

El Señor o Señora del Cerro es, como su nombre lo dice, el espíritu de la montaña, amo, dueño y señor de todo cuanto existe en ella. Se concibe como una persona extremadamente rica y poderosa, a quien se recurre especialmente en peticiones de fertilidad. Es muy fecunda, y es también considerada como la "Madre Tierra". Es común que a este espíritu los "costumbreros" suelan identificarlo con el nombre del santo patrón del pueblo.

Cada cerro importante tiene su dueño, sea masculino o femenino. En Chapultenango, por ejemplo, el cerro Gavilán se cree que está gobernado por un joven muy apuesto y poderoso llamado Saspalangui (Saspa es adjetivo que quiere decir de "excelso", y langui, es un nombre propio); es decir, "Langui el excelso". Saspalangui es muy enamorado, y corteja a otros cerros femeninos; especialmente mantiene amoríos con la dueña del cerro Tsitsungotsök (Cerro Chichón, es decir, el volcán Chichonal). Los encuentros entre Saspalangui y la Señora del Volcán son muy escandalosos: a menudo tiembla, ruge la montaña y arroja fumarolas; pueden considerarse encuentros explosivos.

En síntesis, para obtener abundantes cosechas se invoca a la Madre Tierra. Unas veces se le ofrece comida, "sólo se utilizaba el corazón, el hígado, los ojos y el cerebro, que se colocaban en una olla nueva de barro 
$y$, si era posible, decorada con pintura de animales como el mono, el águila, el armadillo, la mariposa y el jaguar" (Reyes, 2007: 33). En la década de 1970, a raíz de la construcción de la presa Chicoasén, el reporte de salvamento arqueológico registró cincuenta y tres cuevas, de las cuales veintitrés contenían vestigios arqueológicos (básicamente cerámica) y dieciocho contaban con pinturas rupestres, todas ellas en color rojo. En todos estos sitios los antiguos pueblos acudían a hacer ofrendas y rituales de invocación a sus deidades (actualmente grupos de zoques continúan realizando ritos ancestrales en el Cañón del Sumidero).

Un ejemplo de plegaria dirigida a la Madre Tierra fue recopilado y traducido del zoque al castellano por Jaime Díaz Gómez, proveniente de su padre Miguel Díaz, de 65 años, al celebrar un rito de preparación de la tierra para la siembra en la comunidad zoque de Anexo, municipio de Rayón, Chiapas, en abril del 2002. La oración reza así:

Madre Tierra, ante mi Dios presente voy a hablarte y a pedirte permiso. Ante mi Dios presente como madre de todos los dones que existen. Voy a trabajar y a caminar sobre tu suelo, sobre tu corazón, porque así los destinó mi Dios. No te enojes, no te sientas mal, aquí es el lugar donde voy a trabajar, ya que soy un humilde trabajador de mi madre tierra. Durante el tiempo que trabajaré, a tus animales y crianzas quítalos de aquí, guárdalos por un tiempo para no causarles y causarme problemas, porque aquí es donde haré mi humilde trabajo. Voy a cultivar mis alimentos para pasar los días porque tengo que comer para sobrevivir; aquí es donde estarás a mi lado y permanecerás, mi Dios. Tú vas a impedir y alejar aquellos malhechores, nahualeros y hechiceros para turbarlos y convertirlos en enemigos tuyos. Vas a utilizar tu majestuosa y antigua sabiduría como arma para protegerme de todos los peligros y males. Así es como te imploro, mi Dios, para que me cuides en los días de trabajo, ya que aquí es donde van a caminar mis hijos, mis frutos, tus hijos, tus frutos, durante el tiempo que viviremos sobre la tierra. ${ }^{8}$

Después de hacer esto, el señor Miguel Díaz sacrificó aves y dio de comer y beber a la tierra, como agradecimiento por sus abundantes cosechas. En especial recuerda haber cosechado algunas "mazorcas papá", es decir, mazorcas gemelas, cuyos granos utilizó parcialmente como semilla para posteriores siembras, y otra porción la usó como ofrenda para su altar familiar, en agradecimiento por los favores recibidos. Según su concepción no había duda de que sus plegarias habían sido escuchadas. Para él esta evidencia demostraba, con hechos, la existencia del Señor del Cerro.

\section{b. Invocación a Pyogachu'we ("la Vieja que Arde"), Señora del volcán Chichón}

Pyogbachu'we (Py, pronombre de segunda persona en singular, Ogba equivale a "arde", y Chu we a "abuela") es "la abuela que arde". Es la dueña del cerro del volcán Chichón. Tuvo violenta actividad explosiva del 28 de marzo al 5 de abril de 1982.

Antes de que el volcán Chichón hiciera erupción, los zoques más tradicionalistas ya habían consultado al oráculo y recurrido a otros vaticinios para conocer la suerte que correrían sus pueblos ante el inminente evento explosivo.

Justamente en el sector de "costumbreros" del pueblo de Ocotepec, corrió el rumor de que habían advertido, a través de sueños, que San Marcos Evangelista, patrón del pueblo, no podría ganar la batalla al pelear contra la Dueña del Volcán, toda vez que San Marcos "ya se cansaba", es decir, estaba viejo, y sería incapaz de defender al pueblo de la erupción volcánica.

En estos sueños habían advertido que San Marcos "estaba perdiendo poder", que su nahual, el "tigre" alado y la espada flamígera no representaban ninguna amenaza para la Señora del Volcán, pues ella era más poderosa, toda vez que podría inundar de petróleo, 
fuego, gases, arena y rocas incandescentes no sólo a los pueblos zoques, sino al mundo entero. El pronóstico era que las comunidades aledañas al complejo volcánico desaparecerían. Habría, entonces, que calmar la ira de Pyogbachu we, ofreciéndole sacrificios a manera de víctimas alternas.

La delicada tarea se le encomendó a los ancianos "costumbreros". La misión era aplacar la ira de la Señora del Volcán a través de ofrendas. Así, un grupo de ancianos se dirigió al ejido Guayabal y a la colonia Volcán, muy cerca del volcán Chichón, lugar donde "había dibujos en piedras y escrituras jeroglíficas [...], bancos de arena volcánica y restos de cerámica de barro, ollas de barro, figurillas de 20 a 30 centímetros de altura, con características de ofrendas de adoración de sus dioses, a una profundidad de 20 a 50 centímetros, [sitios] poblados por los antiguos zoques..." (Reyes, ibid: 32). Ahí hicieron sacrificios de aves y pidieron piedad a la Madre Tierra. Ejecutaron música de flauta de carrizo y tambor, bailaron, rezaron y comieron en honor a Pyogbachu we.

Un fragmento a la invocación a la "Vieja que arde" dice así:

Señora que celebra sus enojos con fiestas, señora de noches multicolores y días oscuros. Niña, joven, señora y anciana de belleza temida. Señora que apaga las estrellas y enciende los rayos, que duerme despierta, que recuerda el olvido.

Te recordamos como piedra preciosa, como fino pedernal.

Como luz de la oscuridad,

Como víbora de fuego. Ven a nosotros.

Los "costumbreros" oraban en silencio, dirigiendo la ceremonia. Al concluir, regresaban en fila india sin volver la mirada hacia atrás, hasta nueva orden. Se tiene la firme convicción que el volcán llama a la persona por su nombre y que, en caso de voltear, el sujeto es atrapado por el "encanto" y convertido en piedra.
La petición, a decir de los "costumbreros", fue escuchada, pues tres meses antes de hacer erupción el volcán, la mismísima Pyogbachu'we bajó a las aldeas ubicadas en el complejo volcánico a invitar a su fiesta de cumpleaños. Ella prometió a sus invitados halagarlos con bastante cohetería, luces multicolores, castillos y bombas. Aceptar el convite garantizaba una vida eterna en el mundo de Tsu'an, donde todo es fiesta y la vida se embelesa. Rechazarla, significaba una vida llena de sufrimientos terrenales.

Gracias al aplacamiento de la ira de la Señora del Volcán, San Marcos de alguna manera hizo valer su poder, pues durante el proceso eruptivo Ocotepec no fue destruido en su totalidad, como sucedió con otros muchos pueblos; aunque fue evacuado, se mantuvo en fase de excepción. Por otro lado, Pyogbachu we celebró su fiesta de cumpleaños; quienes fueron los invitados se consideraron dichosos por asistir y ahora gozan de felicidad eterna.

Los "costumbreros" demostraron la existencia real de Pyogbachúwe, y su poder destructivo quedó de manifiesto. Al mismo tiempo, gracias a que su ira fue menguada con las ofrendas celebradas en su honor, se consideró que San Marcos negoció la salvación de su pueblo.

En contraste, tanto para católicos como para adventistas, la Señora del Volcán es identificada como una figura diabólica. De hecho, algunos zoques están seguros de que San Marcos colocó su león alado con su espada flamígera en lo alto de la fachada de la catedral de Tuxtla Gutiérrez, viendo hacia el Norte, y vigilando los movimientos que hace la Señora del Volcán. Nuevas batallas están por librarse.

\section{c. Evento público social: ceremonia al Padre Sol}

Los programas culturales de tipo oficial son espacios donde tiene cabida la celebración de ceremonias rituales ancestrales de los pueblos indígenas, como muestra del folclore nativo, sin mayor satanización y que, además, 
refuerzan la identidad del grupo. En ellos se recrea lo que se considera debió ser la práctica religiosa de estos pueblos, se ensaya y monta con fines teatrales.

Este es el caso de la puesta en escena de la ceremonia "Al Padre Sol", rito en el que se teatraliza el inmenso respeto a la máxima deidad, pues "a los dioses se les debe mucho y que sin respeto y sin ofrendas al dios Sol se acabaría todo de lo que hay sobre la tierra y de más allá" (Díaz, s/f: 1).

Esta ceremonia se llevó a cabo en conmemoración al 28 aniversario de la erupción del volcán Chichón, el día 23 de marzo de 2010, en las instalaciones del Centro de Difusión Cultural de la Universidad Intercultural de Chiapas, con sede en San Cristóbal de Las Casas, Chiapas. El evento fue convocado por el Comité de Lengua y Cultura Zoque (CLCZ), la Comisión Nacional para el Desarrollo de los Pueblos Indígenas (CDI) y la Universidad Intercultural de Chiapas (UNICH).

Participaron en la ceremonia alrededor de doce integrantes, más el personaje principal que hizo las veces de sacerdote. Todos vestidos a la usanza azteca: los hombres con taparrabos, penachos y pulseras; las mujeres, con vestidos largos adornados con grecas de colores y penachos menos elaborados. Todos usando incienso, y haciéndose acompañar por un ídolo de piedra y mazorcas de diversos colores. Un grupo de músicos acompañó la ceremonia ejecutando música de carrizo, tambor, violín y guitarra.

La ceremonia se efectuó con la siguiente plegaria:

Palabras al papá Sol:

Mi señor,

mi padre,

tú que iluminas a la tierra,

tú que te levantas todos los días

tú que nos iluminas,

tú que nos envías el bienestar.

Hoy te pido,

te encomiendo y te entrego esta ofrenda de este pueblo tuyo, este perfume del árbol sagrado para ti. Te sahumamos con todo el pueblo aquí reunido ante ti, recibe todo lo que han traído en tu presencia.

Así como en la antigüedad tu pueblo te espera para que les envíes tus bendiciones, tu sagrada sabiduría, tu sagrada palabra, tu sagrada vida.

Todos los días envíanos el buen viviry la salud, protege a nuestros hijos, protégenos de las enfermedades, que tu pueblo se multiplique, que nuestro trabajo sea grande, haya abundancia en nuestra cosecha, que las semillas que depositamos en el corazón de la madre tierra sea fecunda, que nunca nos falte nada, que nunca haya pleito entre nosotros, ni desigualdad, ni odio ni venganza. Esto es lo que el pueblo te pide papá que estás en el cielo, que nos iluminas todos los días. Así es.

Üj ngomi,

Üj jara,

Mijte nisü'npapü yü' nasakopajk,

Mijte xa'pa tuntum jama,

Mijte dü nisü'nütyanpapü,

Mij dü gü’wejatyampabü te wüpü ijtkuy,

Yüti mij ngü’japy'tsi,

Mij ntsamepüjkpa'tsi, mij ntsükütsipa'tsi yü’ wendiram mij nkupkuyis dyosandam, Yü' masan kuyjis sa'sapü 'yoma mijchkoroya.

Mij ngüjo'kütyampa’tsi yü’ mumu mij ngupkuyji’n yü'ki tu'mupü mumu jamase, tsüküpüjkayaü mumu tiram mityajupü'is ndxajkayae mij wi'nanomo.

Te'se ya'ajkpü iri'omose, mij nkupkuyis jyo'kpa wü'kü nkyü'wejayaü mij oye'ajkuy, mij masan ntsame,mij masan mujsokyuy, mij masan otowe, mij masan ntsüki, mij masan ijtkuy.

Tumtumjamadüyü’wejatymütesa'sapüijtkuy,yajk sone ajü mij nkupkuy, suñi yajktsojkyaü üj uneram, Jana 'yirü ka'kuy, yajk sone'ajü üj yosandam, yajk tsojkyaü tü’müyuaü te puj nijptampüpü’tsi te mayi nasakopajkis kyujkpajküsi, mumu jama yajk irü mumu tiyü, umü yajk irü te ji’ wyüpü tiyü, te onguy. 
Te kijpkuy y eyara'mpü tiyü ji dyajk tu’najepü te kupkuy,

Te'sere jujchenemijnke'jatyawü üjjara tsajpomopü (Román Díaz Gómez, zoque de Nuevo Esquipulas Guayabal, Anexo de Rayón, Chiapas).

\section{Palabras finales}

Los "costumbreros" conforman un sector religioso que practica un catolicismo muy particular, con fuerte influencia de la visión indígena de sus deidades ancestrales. El largo y violento proceso de evangelización que han experimentado los pueblos no ha podido borrar del todo las prácticas antiguas de la religión nativa, a lo sumo se ha resignificado, pues la concepción y práctica cultural de sus ritos obedece a la visión que tiene del Supramundo y del Inframundo. Para ellos, sus dioses están vivos, y algunas veces visten ropaje de santos católicos. Sin embargo, desde la perspectiva cristiana se suele identificar a sus dioses bajo la figura del Diablo, por lo que sus invocadores son acusados de ignorantes, idólatras o brujos.

Por ejemplo, cuando un "costumbrero" reza al Rayo Azul para pedir abundantes lluvias, o al Rayo Blanco para calmarlas, los otros credos los descalifican, pues identifican a las deidades nativas con el mal. Sin embargo, en situaciones de excepción, como la que experimentaron con la erupción violenta del volcán Chichón sucedida en marzo y abril de 1982, no importaba quién salvaría a la población, si las deidades zoques o los santos cristianos, sino que se amalgamaron ambas concepciones con el fin de sentirse protegidos independientemente de la adscripción religiosa.

Por otro lado, el "costumbrero" percibe en algunos santos católicos, especialmente los que se representan como viejos, que éstos ya se cansan, y en consecuencia "están perdiendo poder", por lo que es preciso auxiliarse de las deidades nativas, pues todos ellos son extremadamente poderosos, jóvenes y, en especial, están vivos, no envejecen y por lo tanto no mueren. Evidentemente, esta concepción irrita al sector católico, y es una de las principales por la cual entran en conflicto ambas creencias y prácticas religiosas.

El "costumbrero", así, vive en un mundo ambivalente; por un lado, es motivo de burla y discriminación por parte de otros credos religiosos, pues es calificado como idólatra, ignorante, brujo, "borracho" y "atrasado".. Pero por otro lado, para fines culturales estos individuos son vistos como los depositarios de la tradición, los que dan identidad al grupo, los que mantienen viva la costumbre y las tradiciones religiosas nativas..

Sin embargo, se sea costumbreros o no, la creencia en lugares encantados y en seres sobrenaturales (llámense Diablo o cualquier otra denominación cristiana) es de dominio público. La tradición oral en las comunidades está plagada de estos personajes.

Se ignora el número de "costumbreros", pues es una denominación local. Los registros estadísticos, en consecuencia, no los captan, pues esa categoría religiosa no existe para fines analíticos. Por otro lado, la celebración de ritos en eventos públicos sociales, en especial los de carácter oficial, ha permitido difundir la "costumbre" que aún mantienen los pueblos originarios, sin temor de ser reprendidos por prácticas "paganas". Así, en estos espacios públicos recrean algunas danzas antiguas y otras ceremonias propiciatorias donde invocan libremente a sus deidades antiguas.

La religiosidad nativa zoque ha sido satanizada, entre otras cosas, porque se desconoce su cosmovisión; a pesar de ello ha sobrevivido, en parte de forma clandestina o en tanto que su práctica ha sido estigmatizada. Es preciso entonces hacer una investigación profunda que brinde elementos que nos permitan conocer, entender y explicar la cosmovisión indígena respecto de la religiosidad zoque, y entender más la práctica de los "costumbreros". 


\section{Notas}

${ }^{1}$ De hecho, los zoques, especialmente los de Copainalá, como grupo étnico, se autodenominan suñipöt. Es decir, "los Hermosos". (Véase Villasana, 1995: 209).

2 Para mayor información véase Reyes, 2008.

${ }^{3}$ En la cosmovisión zoque, la edad está estrechamente relacionada con el ciclo solar. Así, las deidades por las mañanas son niñas, al medio día, mozas, y por las tardes, maduras; nunca mueren.

${ }^{4}$ En la cosmovisión mixe, parientes cercanos a los zoques, el rayo es percibido como “... un Señor muy rico, dueño de la lluvia, de los animales del monte. Manda a regar la milpa y da órdenes donde echar mucha agua y dónde nomás lo suficiente. Quien no hizo sacrificios va a tener mala cosecha, su milpa no será cuidada y regada" (Ballesteros y Rodríguez, 1974: 66).

${ }^{5}$ En realidad no hay una opinión que unifique los criterios de color, origen y acciones de los rayos, muy en especial del rayo negro. Hay quienes dicen que éste no existe, sino suele confundirse a menudo con el toki (cometa), cuyo impacto es fulminante. En la cosmovisión zoque fue el toki, y no los rayos, el único capaz de destruir el cerro de la abundancia, y puso al descubierto el maíz. Véase Villasana, 2009.

${ }^{6}$ El "Dueño del Cerro", en la opinión de Jorge Báez (2003: 591), "vigila todas las riquezas guardadas en su interior —alimento, maderas, animales, dinero...-y los humanos deben realizar rituales propiciatorios para obtenerlas"

${ }^{7}$ Sobre el particular se recomienda la lectura de Dolores Aramoni (1992).

${ }^{8}$ Comunicación personal de Jaime Díaz Gómez, 14 de agosto de 1998.

\section{Bibliografía}

Aramoni Calderón, Dolores (1992), Los refugios de lo sagrado. Religiosidad, conflicto y resistencia entre los zoques de Chiapas, México: Consejo Nacional para la Cultura y las Artes.
Báez-Jorge, Félix (2003), Los disfraces del diablo, México: Biblioteca Universidad Veracruzana.

Ballesteros R. Leopoldo, Rodríguez E. Mauro (1974), La cultura mixe. Simbología de un humanismo, México: Editorial Jus.

Córdoba O., Francisco R. (1975), "Ciclo de vida y cambio social entre los zoques de Ocotepec y Chapultenango, Chiapas", en Los zoques de Chiapas, Alfonso Villa Rojas, José M. Velasco Toro, Félix Báez-Jorge, Francisco Córdoba y Norman Dwight Thomas, México: Instituto Nacional Indigenista, pp. 189-220.

Díaz Gómez, Román, (s/f), "Ofrenda zoque”, Ms.

Reyes Gómez, Laureano (2007), Los zoques del volcán, México: Comisión Nacional para el Desarrollo de los Pueblos Indígenas (CDI).

Reyes Gómez, Laureano (2008), "La visión zoque del Inframundo", en Revista Española de Antropología Americana, núm. 2, vol. 38, pp. 97-106, España.

Villasana Benítez, Susana (1995), Identidad étnica entre los zoques de Chiapas. Estudio comparativo. Tesis de Maestría, México: ENAH.

Villasana Benítez, Susana (2000), "The presence of Corn in Myths. The Ke'n miomo. Zoques of Chiapas", en Latin American Indian Literatures Journal. A Review of American indian Texts and Sutidies, núm. 1, vol. 25, Penn State Greater Allegheny, pp. 1-18.

\section{Consultas en línea}

Rodríguez León, Félix, "Sobre el costumbre zoque", [consultado: 03 de mayo de 2010]. Disponible en línea: http://pacificosur.ciesas.edu.mx/fichas/ conte28.html.

“Zoques de Chiapas". [consultado: 03 de mayo de 2010]. Disponible en línea: http://pacificosur.ciesas.edu.mx/ fichas/opcion28.html.

Grupo de zoques continúan realizando ritos ancestrales en el Cañón del Sumidero. [consultado: 15 de mayo de 2010]. Disponible en línea: http://www. diariodepalenque.com/nota.php?nId=17116. 